\title{
Unilateral Third/Accessory Head of the Gastrocnemius Muscle: a Case Report
}

\author{
Tercera Cabeza Unilateral del Músculo Gastrocnemio: Reporte de un Caso
}

\author{
Mitesh R. Dave; Vaishali Kiran Yagain \& Samir Anadkat
}

\begin{abstract}
DAVE, M. R.; YAGAIN, V. K. \& ANADKAT, S. Unilateral third/accessory head of the gastrocnemius muscle: a case report. Int. J. Morphol., 30(3):1061-1064, 2012.

SUMMARY: The superficial muscle group of the posterior compartment of leg forms a powerful muscular mass in the calf. The two-headed gastrocnemius is the most superficial muscle of this group, and forms the proximal, most prominent part of the calf. Gastrocnemius muscle exhibits numerous variations in the origin and/or insertion. The present report describes the incidental occurrence of the third/accessory head of gastrocnemius muscle in the left lower limb. During routine educational dissection of a 54-year old American female cadaver in the Anatomy lab of the Medical University of the Americas, Nevis, West Indies, we found an unusual 10.8 $\mathrm{cm}$ long muscle in the left popliteal region, attached proximally to the lateral aspect of the popliteal surface of femur, and distally terminated as a tendon which was attached at the junction of the medial and lateral heads of gastrocnemius muscle. No such variation was found on the right side. This is described as a case of third / accessory head of gastrocnemius muscle.
\end{abstract}

KEY WORDS: Third/Accessory head of gastrocnemius; Popliteal; Tensor fascia suralis; Plantaris; Soleus.

\section{INTRODUCTION}

The gastrocnemius muscle is a fusiform, two-headed, two-joint muscle, with the medial head slightly larger and extending more distally than its lateral partner. Proximally, the medial head is attached to the popliteal surface of femur, superior to medial condyle, whereas, the lateral head to the lateral aspect of lateral condyle of femur. The two heads come together at the inferior margin of the popliteal fossa, where they form the inferolateral and inferomedial boundaries of this fossa (Moore et al., 2011).

Variations in muscles are quite common and frequently seen during routine dissection of cadavers. Many or most variations are totally benign; some are errors of embryologic developmental timing or persistence of an embryologic condition. Some of these variations may seriously compromise parts of the muscular, vascular, nervous, skeletal and/or organ systems (Gupta \& Bhagwat, 2006).

The third head (Caput tertium) is the most common variation of the gastrocnemius muscle (Gupta \& Bhagwat; Bergman et al., 1995).
In the present case report, we discussed the existence of the third/accessory head of gastrocnemius muscle from phylogenetical, anatomical and clinical points of view.

\section{CASE REPORT}

During routine educational dissection of the lower limb of a 54-year old American female cadaver, a variant muscle was found in the left popliteal region. After careful dissection and clearing the boundaries of the popliteal fossa of left side, this muscle was found close to the roof of the fossa. It was further cleaned and traced throughout to locate its attachments and course (Fig.1).

The muscle was running straight vertically, attached proximally by its fleshy belly to the lateral aspect of the popliteal surface of femur, just adjacent to the plantaris muscle. It then coursed down, running besides and just medial to plantaris, superficial to tibial nerve (from which it received a branch) and popliteal vessels. 


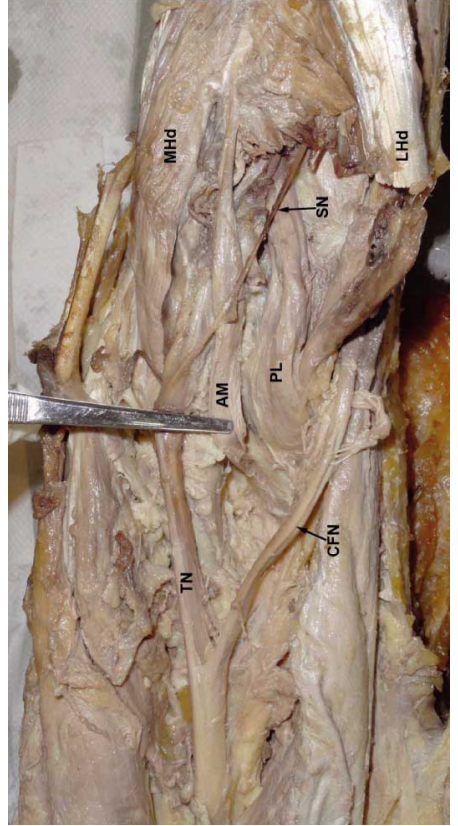

Fig. 1. illustrates the attachments of the third/accessory head of gastrocnemius muscle. AM=third/ accessory head of gastrocnemius, MHd=Medial head of gastrocnemius, LHd=Lateral head of gastrocnemius, $\mathrm{Pl}=$ Plantaris, $\mathrm{TN}=$ Tibial nerve, $\mathrm{CFN}=\mathrm{Common}$ fibular nerve, $\mathrm{SN}=$ Sural nerve.

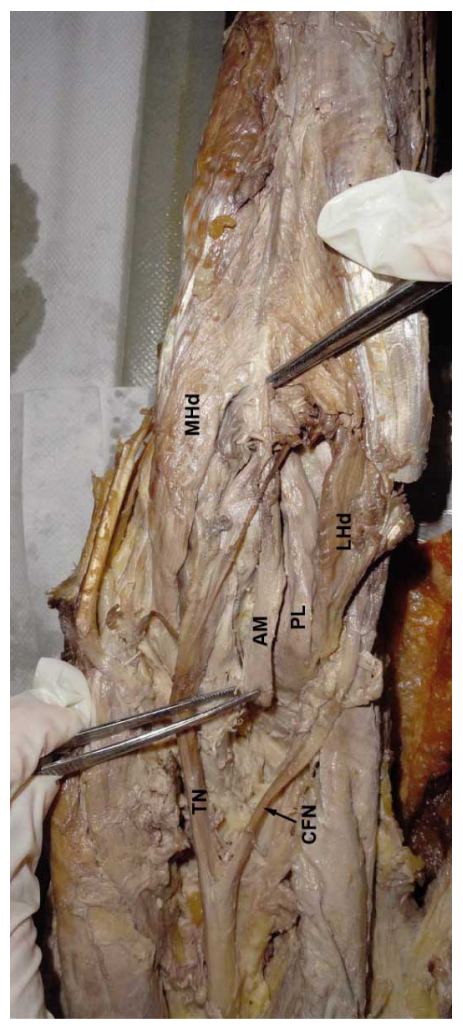

1062

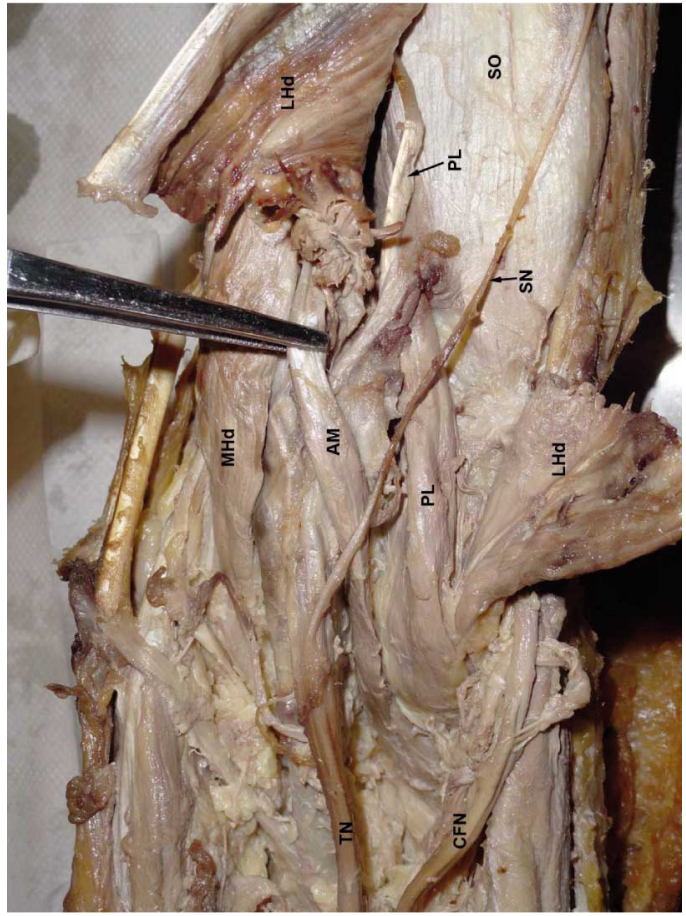

Fig.3 illustrates the reflected lateral head of gastrocnemius to show the relation of the third head with plantaris and soleus muscles, and neurovascular structures. $\mathrm{AM}=$ third/accessory head of gastrocnemius, MHd=Medial head of gastrocnemius, $\mathrm{LHd}=$ Lateral head of gastrocnemius, $\mathrm{Pl}=\mathrm{Plantaris}$, $\mathrm{TN}=$ Tibial nerve, $\mathrm{CFN}=$ Common fibular nerve, $\mathrm{SN}=$ Sural nerve, $\mathrm{SO}=$ Soleus.

Distally, it terminated as a tendon which was attached at the junction of the medial and lateral heads of gastrocnemius muscle (Fig. 2). The total length of the muscle was $10.8 \mathrm{~cm}$. The plantaris tendon ran between the gastrocnemius and soleus muscles (Fig. 3). No such variant muscle was found on the right side.

\section{DISCUSSION}

The variant muscle found is described as a third/accessory head of gastrocnemius muscle, because of the fact that it arises from the popliteal surface of femur, and attached distally at the junction

Fig. 2. illustrates the course and relations of the third head. AM=third/accessory head of gastrocnemius, MHd=Medial head of gastrocnemius, LHd=Lateral head of gastrocnemius, $\mathrm{Pl}=\mathrm{Plantaris}, \mathrm{TN}=$ Tibial nerve, $\mathrm{CFN}=$ Common fibular nerve. of the two heads of gastrocnemius muscle. The anatomical basis for this is the case reported by Gupta \& Bhagwat, wherein they found an anomalous "Y" shaped muscle 'Tensor fascia suralis', giving origin to the 'Third head' of gastrocnemius muscle instead of joining the fascia of leg, and the 'third head' originating from this muscle instead of the popliteal surface of femur.

The third head (Caput tertium) is the most common variation of the gastrocnemius muscle, also described as Gastrocnemius tertius (Bergman et al., 1995). Kelch (1813) is the first to describe the third head. Its overall frequency ranges between $1.7 \%$ to $5.5 \%$.

Phylogenetically, the gastrocnemius muscle has been considered a muscle of the fibular side of the leg (Bergman et al., 1988). It comes from the calcaneum blastomere and follows an ascending migration towards the inferior femoral epiphysis. The third head may arise from the long head of biceps femoris muscle, linea aspera, lateral femoral epicondyle, knee joint capsule, or the fascia of leg. It may split and arise from more than one region or divide near its termination to join both heads of gastrocnemius. A rare variation where an unusual muscle that leaves the belly of semitendinosus and ends in the tendon that joins the fascia of leg is described as Tensor fascia suralis/ Ischioaponeuroticus (Bergman et al., 1988).

Padmalatha et al. (2011) also reported tensor fascia suralis, that formed a thin tendon distally merging with the intratendinous fibers of medial and lateral heads of gastrocnemius muscle. 
Koplas et al. (2009) carried out a prospective study of 1039 consecutive knee magnetic resonance (MR) examinations, of which 20 (1.9\%) demonstrated an anomalous third head of gastrocnemius muscle which was seen arising near the midline of the posterior distal femur, between the mid and medial aspect, and joining the medial aspect of the lateral head of the gastrocnemius. In all of these patients, the third head coursed lateral to the popliteal vessels, and none coursed between the vessels.

Somayaji et al. (1988) have cited in their literature a case of anomalous muscle which originated from the semimembranosus and biceps femoris muscles and then inserted into the superficial surface of the tendocalcaneus. Similar such reports have been described time and again and mentioned in various literatures.

The plantaris muscle itself can be considered a third head, and may join/merge with medial or lateral heads of gastrocnemius muscle (Upasna \& Kumar, 2011). Thus, it is advocated that the plantaris muscle is a derivative of the deeper portion of the lateral head of the gastrocnemius muscle.

The third head may or may not cross popliteal neurovascular structures or some portions of the neurovascular component before insertion into one head, or the other, of gastrocnemius muscle or its tendon. In the present case, the third/accessory head passed superficial to tibial nerve and popliteal vessels, which may have a compressive effect on these structures. Such variant muscles in the popliteal region may lead to compressive neuropathies involving sciatic nerve or any of its branches (Paval et al., 2005).

Yildirim et al. (2011) have described in their report the co-existence of the bilateral gastrocnemius tertius and accessory soleus muscles in the same cadaver. They have extensively elaborated the potential problem for structures in the popliteal fossa due to these variants. The third head joining the medial head of the gastrocnemius muscle is most commonly cited as causing clinical problems like entrapment syndromes. The characteristic signs and symptoms include leg pain, tenderness in the popliteal fossa and decreased pulsations of the distal arteries. Diagnosis by simple Doppler examination is helpful. Surgical resection of the third head relieves the symptoms.

Having considered the literature available and on comparing the present case, we come to the conclusion that this case is one of the third/accessory head of gastrocnemius muscle, originating from the popliteal surface of femur and attached distally to the junction of the medial and lateral heads of the gastrocnemius. It is possible that this variant muscle could have a compressive effect on the tibial nerve and popliteal vessels, and that the awareness of this may prevent its misinterpretation as a pathological structure by radiologists and surgeons.

\section{ACKNOWLEDGEMENTS}

Our sincere thanks to the faculty members of our university who helped and supported during the writing of this manuscript.

DAVE, M. R.; YAGAIN, V. K. \& ANADKAT, S. Tercera/accesoria cabeza unilateral del músculo gastrocnemio: reporte de un caso. Int. J. Morphol., 30(3):1061-1064, 2012.

RESUMEN: El grupo muscular superficial del compartimento posterior de la pierna forma una poderosa masa muscular. El músculo gastrocnemio de dos cabezas es el más superficial de este grupo y forma la parte proximal, más prominente de la pantorrilla. El músculo gastrocnemio presenta numerosas variaciones en el origen y/o inserción. El informe describe la presencia de una tercera/accesoria cabeza del músculo gastrocnemio, encontrada. durante una disección de rutina en un cadáver de una mujer americana de 54 años, en el Laboratorio de Anatomía de la Medical University of the Americas, Nevis, West Indies. La variación muscular inusual medía $10,8 \mathrm{~cm}$ de longitud y se originaba en la región poplítea izquierda, proximalmente en la cara lateral de la superficie poplítea del fémur, y se insertaba en un tendón que se adhería a la unión de las cabezas medial y lateral del músculo gastrocnemio. La variación no se encontró en el lado derecho. Este hallazgo se describe como un caso de tercera/accesoria cabeza del músculo gastrocnemio.

PALABRAS CLAVE: Tercera/accesoria cabeza del músculo gastrocnemio; Poplítea; Tensor de la fascia sural; Plantar; Sóleo.

\section{REFERENCES}

Bergman, R. A.; Thompson, S. A.; Afifi, A. K. \& Saadeh, F. A. Compendium of human anatomical variation. Baltimore, Urban and Schwarzenberg, 1988. pp.7, 23-4.

Bergman, R. A.; Walker, C. W. \& el-Khour, G. Y. The third head of gastrocnemius in CT images. Ann. Anat., 177(3):291-4, 1995.

Gupta, R. K. \& Bhagwat, S. S. An anomalous muscle in the region of the popliteal fossa: A case report. J. Anat. Soc. India, 55(2):65-8, 2006.

Koplas, M. C.; Grooff, P.; Piraino, D. \& Recht, M. Third head of 
DAVE, M. R.; YAGAIN, V. K. \& ANADKAT, S. Unilateral third/accessory head of the gastrocnemius muscle: a case report. Int. J. Morphol., 30(3):1061-1064, 2012.

the gastrocnemius: an MR imaging study based on 1039 consecutive knee examinations. Skeletal Radiol., 38(4):349$54,2009$.

Moore, K. L.; Agur, A. M. \& Dalley, A. F. Essential Clinical Anatomy. $4^{\text {th }}$ Ed. Baltimore, Lippincott Williams \& Wilkins, 2011. pp.363, 365 .

Padmalatha, K.; Prakash, B. S.; Mamatha, Y. \& Ramesh, B. R. Ischioaponeuroticus/tensor fascia suralis. Int. J. Anat. Var., 4:104-5, 2011.

Paval, J.; Vollala, V. R. \& Nayak, S. Sciatic nerve entrapment in the popliteal fossa: a case report. Neuroanatomy, 4:41-2, 2005.

Somayaji, S. N.; Vincent, R. \& Bairy, K. L. An anomalous muscle in the region of the popliteal fossa: case report. J. Anat., 192(Pt 2):307-8, 1998.

Upasna \& Kumar, A. Bicipital origin of plantaris muscle - a case report. Int. J. Anat. Var., 4:177-9, 2011.

Yildirim, F. B.; Sarikcioglu, L. \& Nakajima, K. The co-existence of the gastrocnemius tertius and accessory soleus muscles. $J$. Korean Med. Sci., 26(10):1378-81, 2011.
Correspondence to: Dr. Mitesh R. Dave

Associate Professor of Anatomy,

Medical University of the Americas, Potworks

Nevis, St.Kitts and Nevis

WEST INDIES

Phone: +1 8697640727

Email: miteshdave30@yahoo.com

m.dave@mua.edu

Received: 25-11-2012

Accepted: 11-04-2012 